Jaime J. Ferrer Forés

Figura 1. Jørn Utzon, Tobias Faber, Mogens Irming: Concurso para el Crystal Palace en Londres, 1946.
Jaime J. Ferrer

Forés.

Profesor Agregado del Departamento de Proyectos

Arquitectónicos de la Escuela Técnica Superior de Arquitectura de Barcelona,

Universitat Politècnica de Catalunya (UPC).

\title{
Jørn Utzon
}

\section{Plataformas y recintos en Højstrup}

Palabras clave: Jørn Utzon, plataformas, Højstrup, Ópera de Sídney.

Este artículo analiza el proyecto del arquitecto danés Jørn Utzon (1918-2008) para la construcción de la Escuela de la Unión de trabajadores daneses en Højstrup, Helsingør (1958-1962), desde las dos propuestas presentadas al concurso, que obtienen el primer y segundo premio, a las versiones del proyecto que desarrolla simultáneamente al proyecto de la Ópera de Sídney (1956-1973). El análisis de la evolución del proyecto de Højstrup permite aproximarse al talento plástico y al universo de extraordinario lirismo del arquitecto, a través de la exploración formal que desarrolla en torno a las plataformas y los recintos, a la relación entre los dos elementos de la escala tipológica, la torre y el cuerpo bajo, al estudio de los mecanismos de acceso mediante la porte-cochère, al sistema de agregación de las casas patio o el papel que desempeña la estructura en el proyecto, en un ejercicio de exploración arquitectónica que fluye desde los concursos, entendidos como laboratorios de experiencias formales, al desarrollo lento y gradual de los proyectos sucesivos atendiendo a la vez el sitio y la pieza tipológica, en una cuidada innovación plástica que reivindica la experimentación constructiva y la integración en el paisaje.

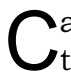
aracterizada por la unión de talento tectónico, refinamiento plástico y voluntad iconográfica, la trayectoria del maestro danés Jørn Utzon (1918-2008) se ha forjado sobre su fascinación por la experimentación constructiva y la integración paisajística en una arquitectura que condensa construcción vernácula y lirismo, obra rigurosa y contexto, y cubre un itinerario tenaz de obras y proyectos que atestiguan la sensibilidad artística y la audacia estructural que fluye desde sus plataformas incipientes de los primeros años hasta la geometría lírica y estandarizada de sus últimas obras (Fromonot 2003: 123).
Valiéndose de las herramientas propias del proyecto como instrumento de investigación, el artículo analiza las referencias, los instrumentos y recursos operativos del proyecto arquitectónico a través del estudio de la evolución del proyecto de la Escuela de la Unión de trabajadores daneses en Højstrup, Helsingør (1958-1962), profundizando en los aspectos del proyecto: la implantación en el sitio, los aspectos funcionales, compositivos y las innovaciones formales planteadas en el concurso y las técnicas planteadas, así como las referencias cruzadas y las influencias que se establecen entre ellas.

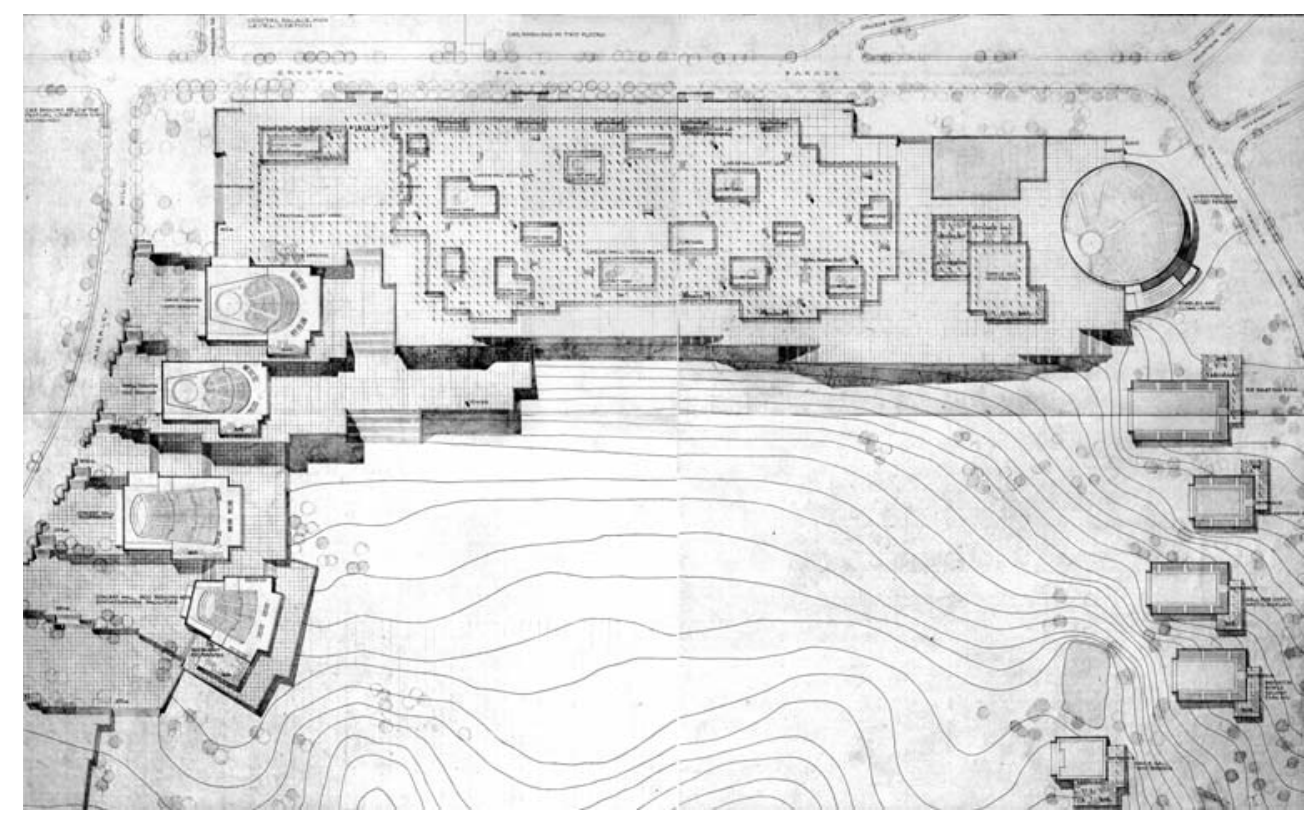



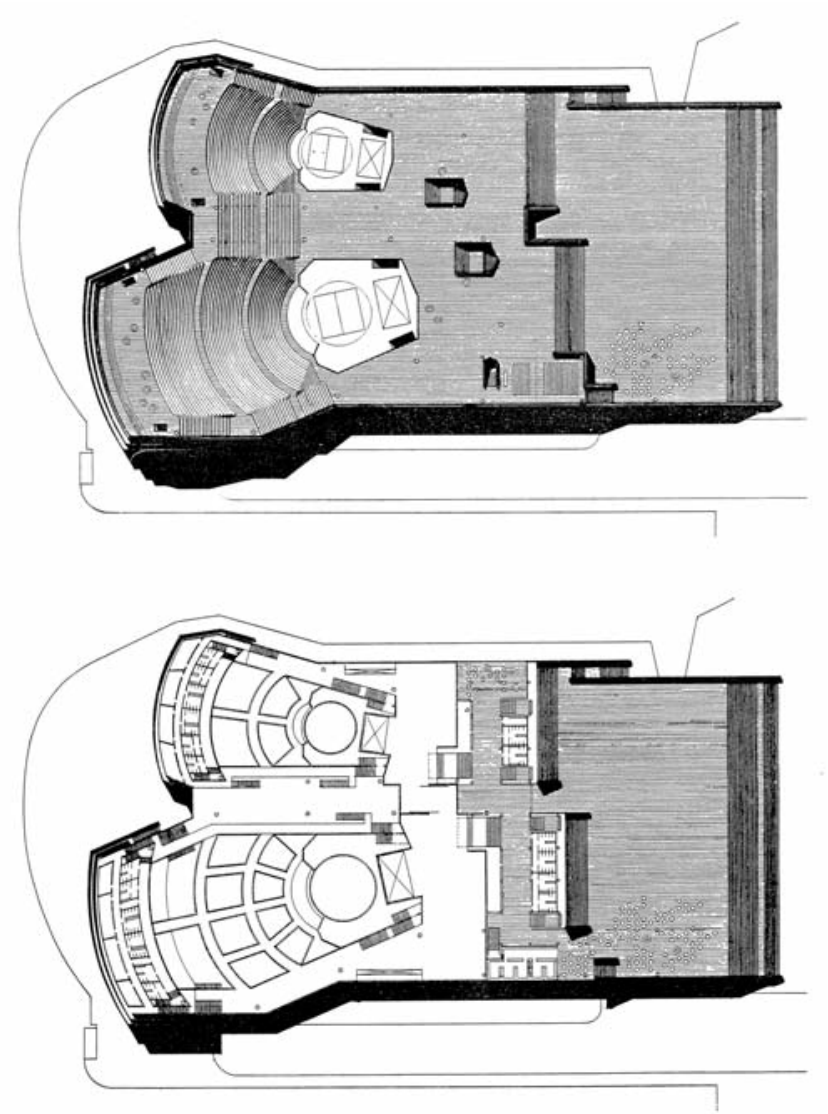

Figura 2. Jørn Utzon: Plataforma y planta basamental del concurso de la Ópera de Sidney, 1956-1973.

\section{Plataformas}

Complementario al muro del recinto como elemento de delimitación espacial, la plataforma constituye un mecanismo para fundar un lugar: preparar un suelo para establecer la construcción sobre un plano horizontal. De su viaje a México en 1949, el arquitecto danés Jørn Utzon (19182008) regresa con gran fascinación por las plataformas que visita en la península de Yucatán. Para Utzon, las plataformas constituyen un formidable concepto arquitectónico (Weston, Pardey 2002: 146).

Las plataformas construidas por los mayas se convierten en una de las experiencias arquitectónicas más importantes de su vida. Frente a la frondosidad de la selva, la plataforma constituye un plano de observación elevado que revela la amplitud del medio y el dominio del entorno. En 1962, publica en la revista Zodiac un artículo titulado "Plataformas y mesetas: ideas de un arquitecto danés" (Utzon 1962: 114117) donde el arquitecto describe la sensación que le produjo pasar de la densa vegetación de la selva al horizonte abierto que se percibe desde las plataformas, y la compara con lo que se experimenta en Escandinavia al ver salir el sol tras varias semanas interminables de oscuridad y lluvia. Además, la plataforma constituye un elemento dinámico en la percepción espa- cial. En el libro titulado La idea del espacio en la arquitectura griega, Rex D. Martienssen afirma "la construcción de una plataforma destinada a eliminar los accidentes de un emplazamiento irregular constituye un paso significativo hacia el pleno control del efecto espacial" (Martienssen 1957: 115). Una serie de suelos concatenados produce un recorrido secuencial que subraya la percepción dinámica de los espacios. La gran plataforma que concibe en el proyecto para el Crystal Palace en Londres (1946) (figura 1) anticipa la plataforma escalonada que unos años más tarde desarrollaría en su obra maestra, la Ópera de Sídney (19561973).

En Sídney, el centro de gravedad de la composición arquitectónica se eleva y la plataforma subraya su condición esteorotómica de pertenencia a la tierra (figura 2). La edificación superpone un nuevo estrato geográfico y revela un nuevo horizonte. La plataforma constituye un plano de observación elevado que revela la amplitud del medio y el dominio del entorno. Además de las plataformas construidas por los mayas, Utzon se sentía atraído además por el mundo clásico y por el modo en que los griegos organizan sus asentamientos urbanos con teatros, estadios y amplias plataformas ceremoniales. Como señala Martienssen, "la plataforma no se limitaba al área cubierta por el templo mismo, sino que tenía por objeto conformar un emplazamiento propio -es decir, establecer una neta separación con la topografia natural del lugar- y por consiguiente abarcaba una superficie considerablemente mayor que la planta del templo" (Martienssen 1957: 116).

La exploración formal que desarrolla en torno a las plataformas se amplia en proyectos a gran escala, en centros históricos y concursos internacionales como el proyecto para la reconstrucción del centro urbano en Berlín (1957), la exposición universal en Copenhague (1959) y la ordenación paisajística que concibe en el concurso de Elviria en Málaga (1960). Con la ambición de relacionar la arquitectura en el medio, concibe edificios insertados en centros urbanos consolidados en los teatros de Zúrich (1964), Madrid (1964) y Wolfsburg (1965) caracterizados por la subordinación al entorno y la experiencia de Sídney. Para Giedion, la construcción del plano horizontal constituye uno de los elementos significativos de la arquitectura de la tercera generación, caracterizada por una relación más fuerte con la arquitectura de la antigüedad (Giedion 1965: 36-47). 

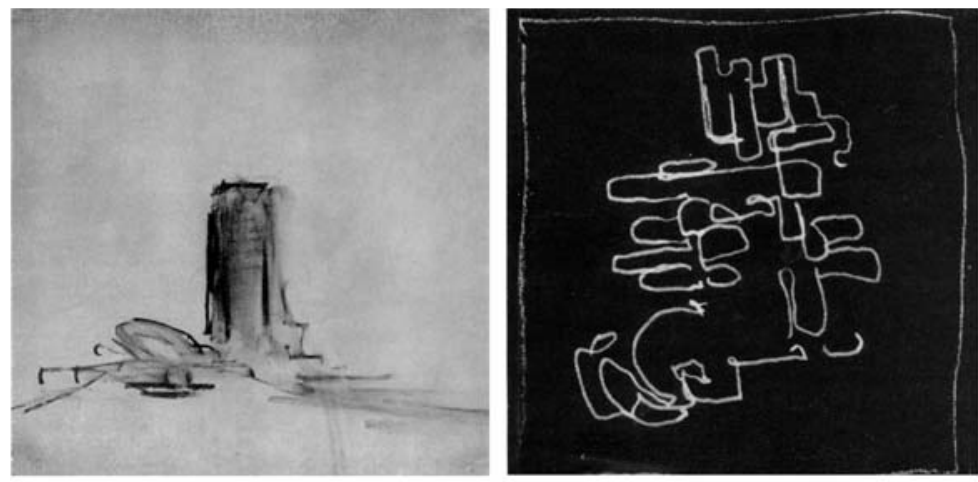

Figura 3. Jørn Utzon. Croquis de la Escuela en Højstrup, 1958.

Figura 4. Jørn Utzon. Emplazamiento, planta y alzados del proyecto para la Escuela en Højstrup, 1958.

\section{E1 concurso como laboratorio}

Para Utzon, los concursos se convierten en un laboratorio de exploración formal en el que confluyen las sucesivas experiencias previas. El talento poético de sus dibujos describe los numerosos proyectos no construidos en las postrimerias de los años cincuenta donde conjuga la vocación topográfica con la audacia estructural que caracteriza la trayectoria de Utzon. La colaboración con Arne Korsmo, en los concursos para la estación central de ferrocarriles de Oslo (1947) y el conjunto de viviendas en Vestre Vika, Oslo (1948), le llevan a participar en la sección noruega del CIAM, PAGON (Grupo de Arquitectos Progresistas de Oslo, Noruega), de la que forman parte Arne Korsmo, Christian Norberg-Schulz, Geir Grung y Sverre Fehn. Para Utzon, "lo que probablemente aprendí más de Geir Grung, y también de Arne Korsmo, es la poesía que consiste en añadir una cosa a un lugar de una manera que se adapte a ese lugar" (Utzon 1986: 9). ${ }^{1} \mathrm{El}$ depósito de aguas emplazado en el paisaje marítimo de
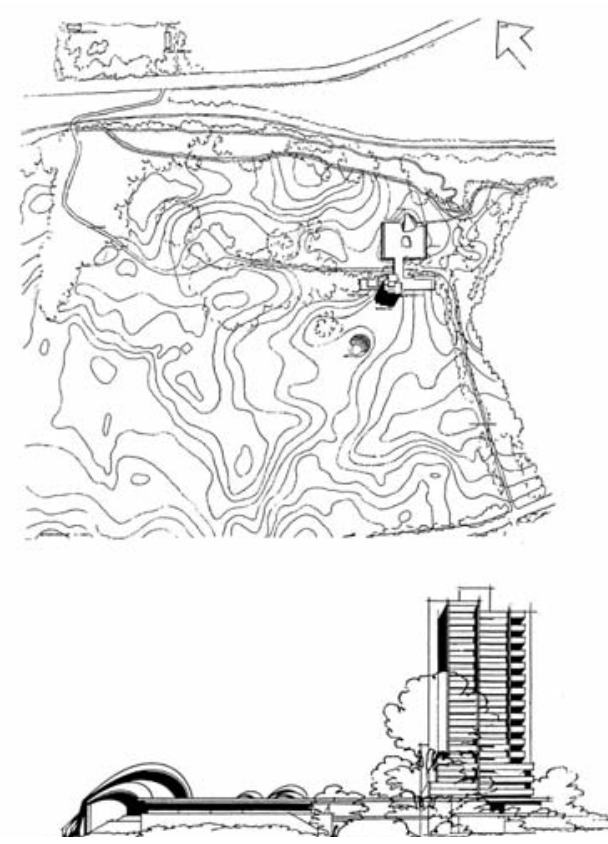

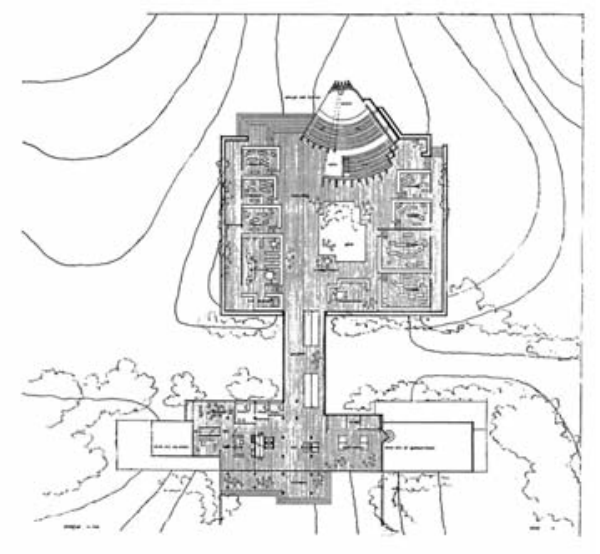

la isla de Bornholm (1946-1951) y el hito monumental del pabellón Langelinie en el ámbito portuario de Copenhague (1953) son dos ejercicios compositivos que abrieron el camino de la escala monumental de Sídney. Tras el concurso de la Ópera de Sídney, Jørn Utzon continuará explorando y ampliando su vocabulario formal con originales propuestas en numerosos concursos, investigando el contrapunto entre las plataformas masivas firmemente ancladas en el terreno y las cubiertas flotantes.

En junio de 1958 se convocó el concurso para la Escuela de la Unión de trabajadores daneses en Højstrup (Birger 1994: 2830). ${ }^{2} \mathrm{El}$ programa, destinado a proporcionar alojamiento a los estudiantes y disponer un aulario y un centro de servicios colectivo, se emplaza en el limite urbano de Helsingør, en el entorno de la edificación histórica Højstrupgård ${ }^{3}$, caracterizada por las amplias áreas libres y los frondosos bosques que se extienden sobre un conjunto de lagos. 4

Mientras en el concurso para la Ópera de Sídney Utzon analizó el sitio mediante las cartas náuticas, fotografias aéreas y con la ayuda de las imágenes contenidas en el programa del concurso, "he estudiado cientos de imágenes, fotografias y planos del sitio", 5 en el proyecto para la Escuela de Højstrup, el emplazamiento está situado junto a la casa del arquitecto en Hellebæk, en un bosque que se extiende sobre la franja litoral del Øresund. Así, la convocatoria del concurso suscitó un gran interés para el arquitecto, tanto por el minucioso conocimiento del sitio, como por la oportunidad de ampliar su explora-

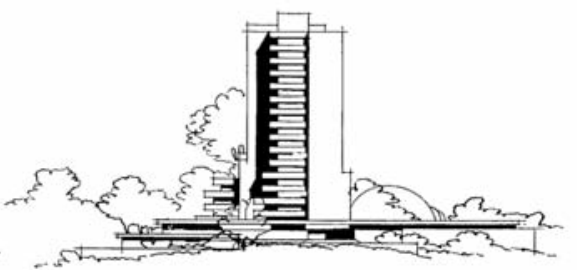




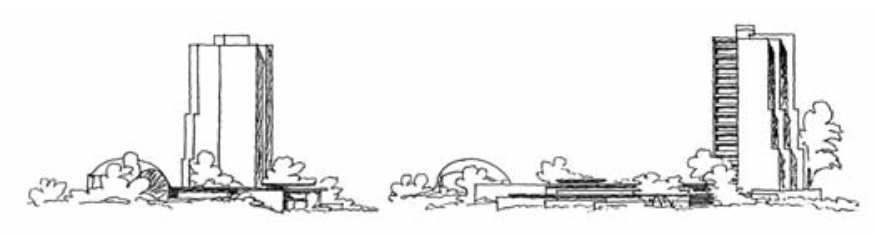

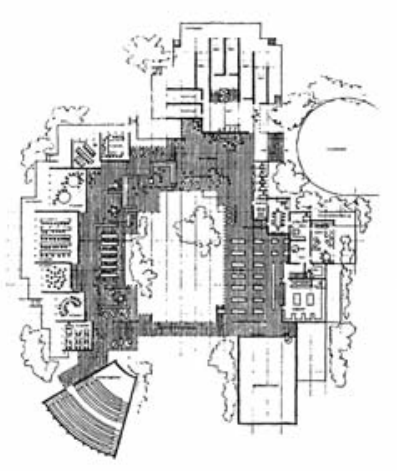
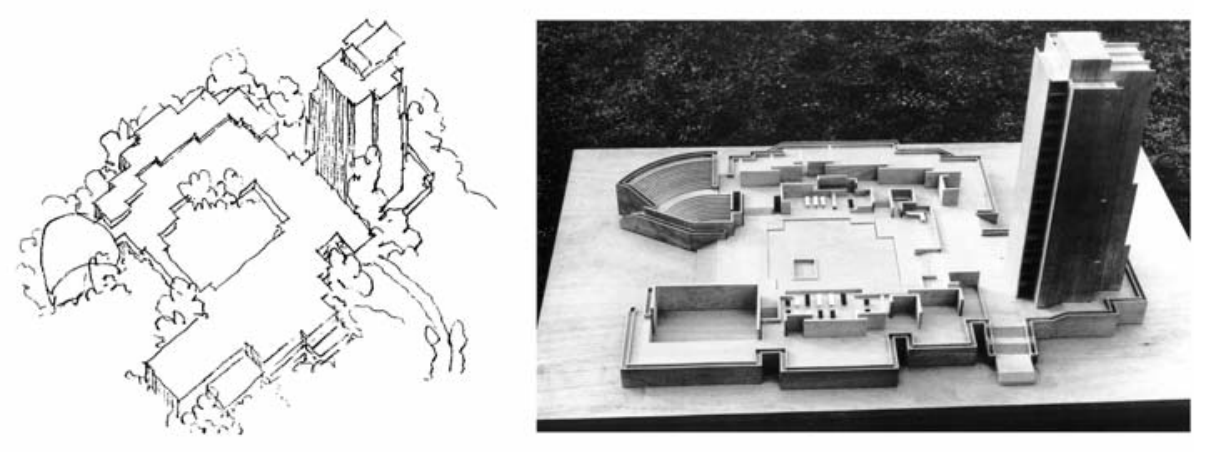

5. Jørn Utzon. Propuesta alternativa de la Escuela en Højstrup. Planta, axonométrica y maqueta, 1958.

Figura 6. Jørn Utzon y Arne Korsmo. Escuela de comercio en Goteborg, 1948. ción formal que desarrolla en torno a las plataformas $^{6}$. Utzon presentará dos propuestas a la convocatoria que ensayan alternativas contrapuestas. Las dos propuestas presentadas a la convocatoria del sindicato se realizarán paralelamente a la elaboración de la primera fase de la Ópera de Sídney y obtendrán el primer y el tercer premio, emulando el éxito cosechado por Alvar Aalto en el concurso para el pabellón de Finlandia en Nueva York de 1939 donde sus tres propuestas recibieron los tres primeros premios. ${ }^{7}$

\section{Torre y plataforma. Primer premio}

Con la identificación "32262", la propuesta se caracteriza por la composición por elementos: la torre de apartamentos emerge sobre un podio fundacional destinado a alojar las actividades del centro (figura 3). El programa residencial de la torre y el bloque educativo se conectan mediante una pasarela mirador que une los dos cuerpos y genera una área protegida de ingreso en el camino, una porte-cochère que alude al

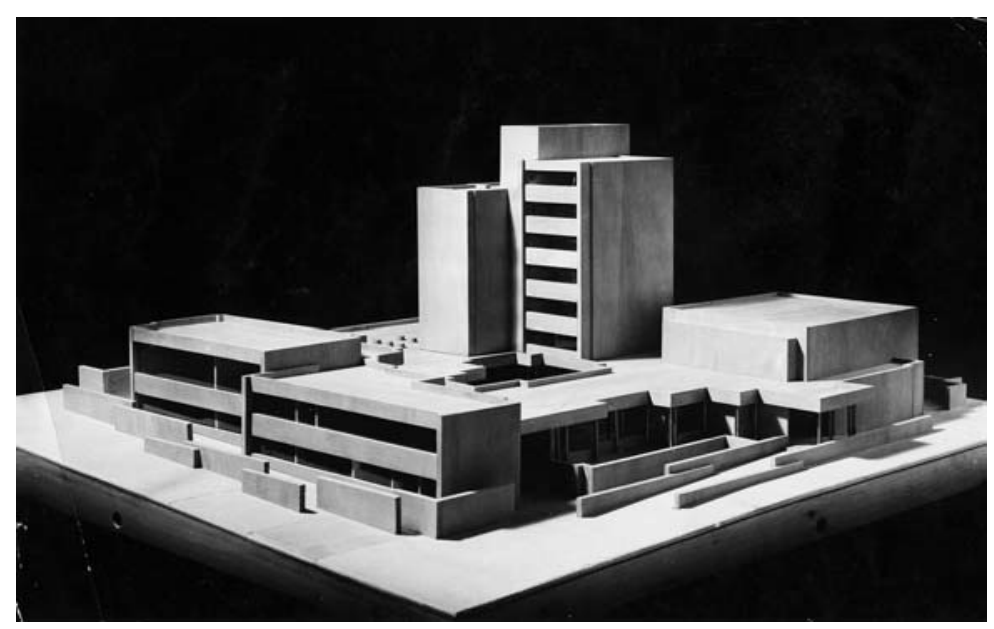

acceso de la casa del arquitecto en Hellebæk (1950-1952).

El programa de la escuela se desarrolla sobre el podio delimitador y fundacional en torno a un patio-jardín en el que destaca el volumen del auditorio. En el desnivel del terreno, el podio prepara el sitio para el establecimiento del centro educativo que se orienta hacia el Øresund. La plataforma se extiende hacia la naturaleza a través de una amplia escalera que se prolonga en el graderio del auditorio evocando la plataforma de la Ópera de Sídney. ${ }^{8}$ El escenario del auditorio, donde convergen los haces de la estructura de las cáscaras, constituye el foco visual y de tensión del proyecto, cuyos rasgos evocan al auditorio de Aalto en la Universidad Politécnica de Otaniemi (1953-1967).

Como contrapunto del cuerpo bajo, la torre se erige sobre un cuerpo longitudinal que aloja el pabellón de gimnasia y la estancia principal para los estudiantes. Compuesta por la yuxtaposición de tres cuerpos en torno al núcleo vertical, la estructura de la torre, que alberga los apartamentos individuales y los dobles, se caracteriza por el núcleo y la estancia común abierta al paisaje y las escaleras que organizan en medios niveles las 15 plantas de la torre (figura 4).

La primera propuesta presenta una alternativa que invierte la posición de la torre y del cuerpo bajo. La torre de los apartamentos se orienta hacia el Øresund mientras el podio donde se establece el programa de la escuela se extiende en torno a un fragmento de la naturaleza, un patio, que acentúa la relación con el medio continuo (figura 5). ${ }^{9}$ 
Figura 7. Jørn Utzon. Tercer premio de la Escuela en Højstrup. Planta y sección, 1958.
La propuesta alternativa retoma la composición ensayada con Arne Korsmo en el concurso para la Escuela de Comercio en Goteborg (1948) y establece la contraposición entre los dos elementos de la escala tipológica, la torre y el cuerpo bajo organizado en torno a un patio, que se extiende sobre el medio físico, y se completa con el volumen del auditorio (figura 6).

\section{Plataforma y recinto. Tercer premio}

Basada en un orden ortogonal y en un sistema modular, la propuesta presentada con la identificación "23533", que obtiene el tercer premio, se establece sobre una amplia plataforma donde se desarrolla la totalidad del programa en extensión, en torno a un sistema de patios (figura 7). Sobre el ámbito de la plataforma se prolonga el programa de la escuela coronado por la levedad de las cubiertas que emergen sobre la horizontalidad del suelo. Estos recintos habitados crean un tapiz complejo de variaciones y deslizamientos donde se van combinando los elementos del programa ilustrando así la exploración de Utzon en torno al patio. La construcción del muro del recinto es una constante fundamental en la obra doméstica de Utzon. Tal como señala Sigfried Giedion, "en el caso de Utzon los limites de sus edificaciones están firmemente establecidos: su flexibilidad reside en el desarrollo de su espacio interior" (Giedion 1965: 36-47). Al igual que en las casas utzonian, el muro es el elemento fundamental de la composición de las casas patio que permite la individualización y la variación de la casa según las necesidades familiares sin perturbar la imagen del conjunto.
Sobre el fluctuante paraje de la costa, la plataforma acentúa las transiciones del terreno ${ }^{10}$. Utzon describe el valor de la plataforma propuesta: "la plataforma del proyecto del instituto se yergue sobre un paisaje ligeramente ondulante y subraya, gracias a su carácter cuadrangular y lineal, los suaves movimientos del paisaje" (Utzon 1962: 140).11 Situado junto al terreno de la Escuela de Højstrup, Utzon describe el proyecto del conjunto de viviendas en Birkehøj ${ }^{12}$ que proyecta en 1960 en los mismos términos, "se ha tomado gran cuidado en seguir en seguir el paisaje y utilizar sus valores"13 (Utzon 1959: 90) definiendo un conjunto escalonado que sigue las transiciones del terreno. Como afirma Christian Norberg-Schulz, los edificios de Utzon "destacan como parte evidente y duradera del lugar"14 interpretando y revelando sus cualidades específicas (Norberg-Schulz 1996: 184).

El terreno artificial obrado en la tierra mediante la construcción de la plataforma subraya el carácter de dominio y genera un frente protegido y aislado. En el perímetro quebrado del centro se emplazan los accesos tangenciales en las inflexiones de los muros. En el interior del recinto, el centro se organiza en una trama bidireccional desarrollada a través de las galerias de comunicación con ensanchamientos $y$ transparencias entre las distintas áreas favoreciendo la interrelación de las actividades y de los usuarios, en un sistema precursor de la organización en tapiz que desarrollará formalmente en su arquitectura aditiva en la década de 1970.
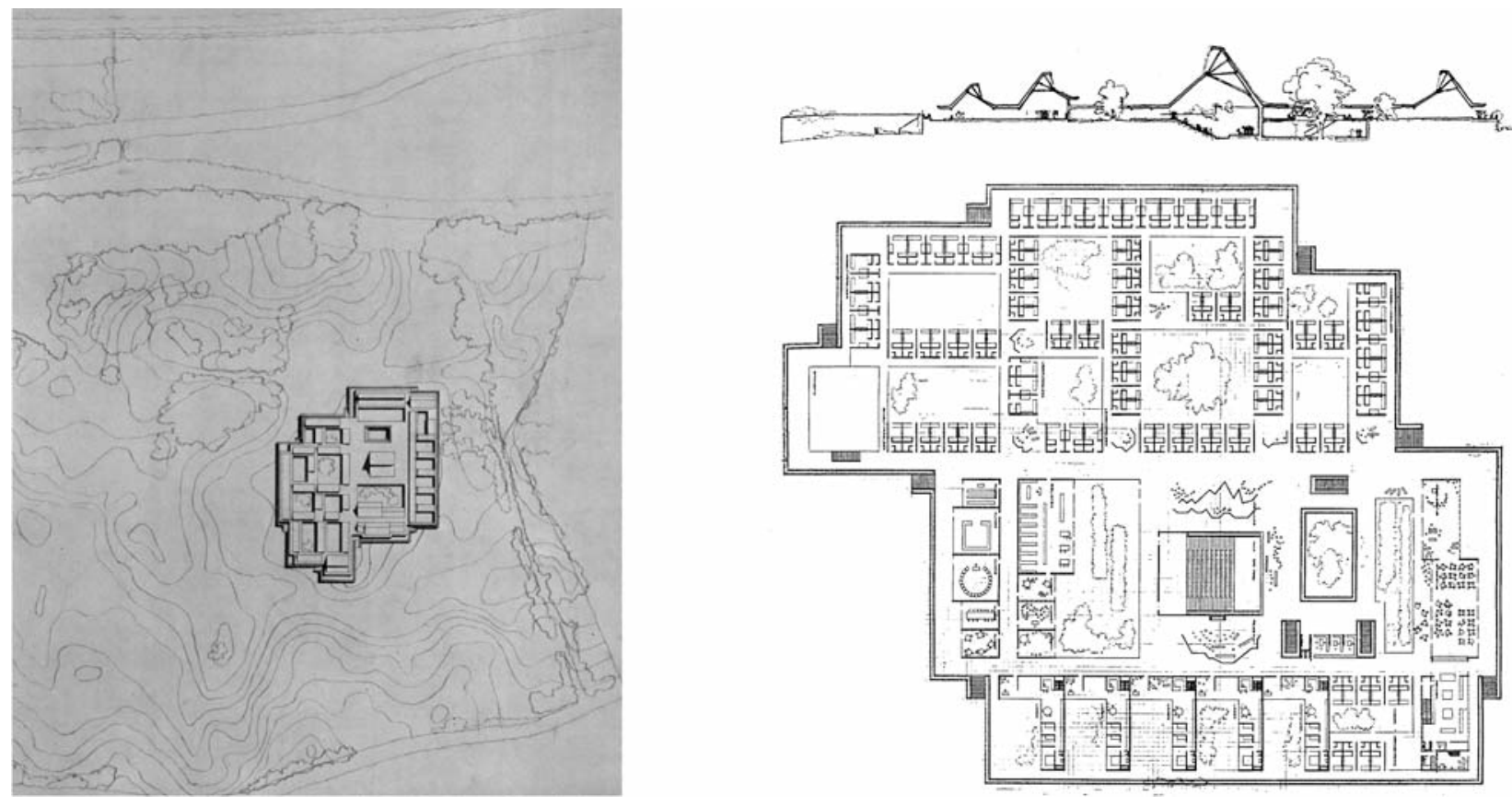
Figura 8. Jørn Utzon. Emplazamiento de la Escuela en Højstrup, 1959.

Figura 9. Jørn Utzon El conjunto de caminos, limites y áreas de aparcamiento. Secciones de los caminos de la Escuela en Højstrup, 1959.

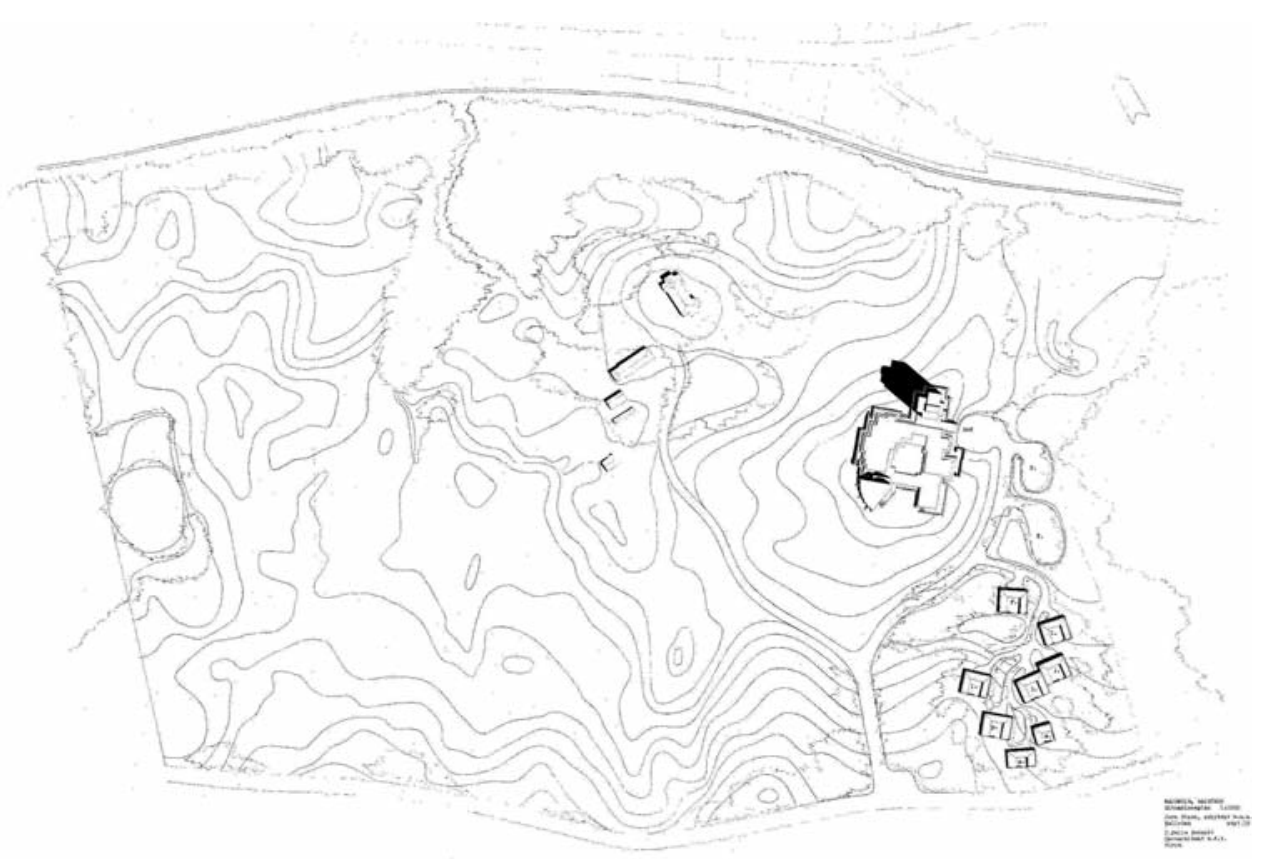

La propuesta se divide en el interior en tres ámbitos. El área central destinada a desarrollar el programa docente de la escuela donde se alojan las aulas, la biblioteca, el auditorio, el área administrativa y la estancia principal abierta al norte sobre el Øresund. En el flanco oriental se sitúan cinco viviendas de los profesores y del personal del centro así como el área de servicios y la cocina. Mientras en el extremo occidental se encuentran el conjunto de apartamentos de los estudiantes desarrollados en torno a una sucesión de patios.

Las actividades educativas, creativas y contemplativas se desarrollan en torno al conjunto de patios que pautan el recinto de la escuela. Sobre la plataforma se entalla el suelo del auditorio, el patio del área administrativa y el ámbito dedicado a la
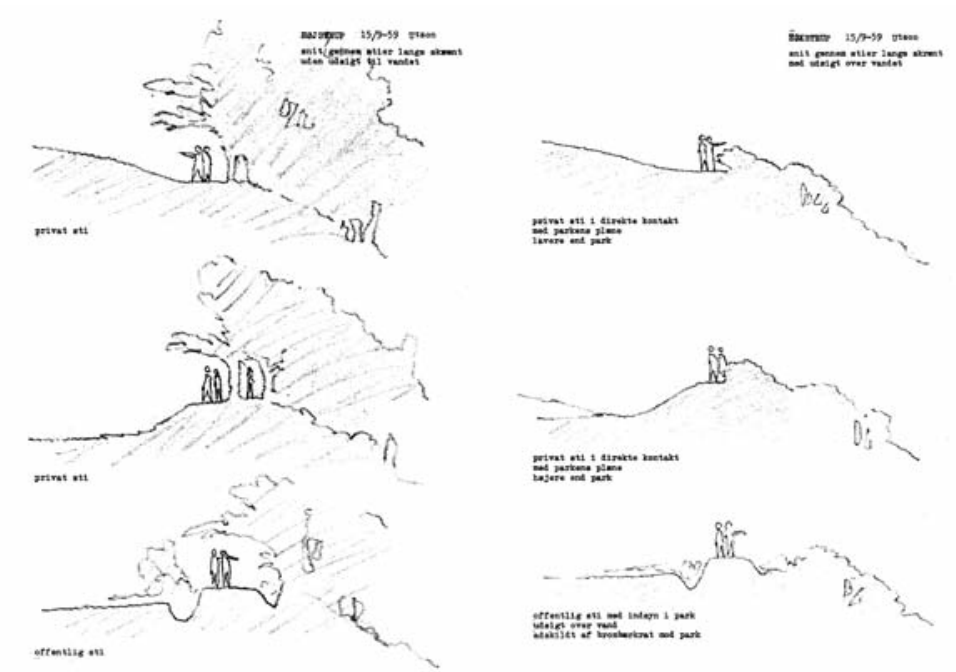

gimnasia, generando un bajorrelieve sobre el plano artificial. Como contrapunto al carácter masivo de la plataforma, la geometria de los faldones de la cubierta caracteriza el volumen de las aulas y canaliza mediante los lucernarios la iluminación cenital. Comparándolo con el proyecto de la Ópera de Sídney, Utzon afirma: "como se muestra en los croquis para la Opera de Sídney y para la escuela secundaria de Helsingør, las cubiertas de formas curvas quedan suspendidos por encima de la plataforma" (Utzon 1962: 114-117).

Las cinco viviendas para los profesores se caracterizan por el patio abierto al paisaje, determinando simultáneamente la privacidad de la vida doméstica y el dominio del entorno. El muro del recinto, que delimita un ámbito privado en el modelo de las casas patio utilizado en los proyectos de viviendas en Skåne (1953) o en las viviendas Kingo (1956), se complementa con el mecanismo utilizado para fundar un lugar sobre la plataforma.

Las relaciones visuales que se producen en el interior del recinto, establecen una sucesión de transparencias e itinerarios que se proyectan hacia la visión panorámica del Øresund adecuándose a la orientación favorable a través del conjunto de patios. El conjunto de las aulas, los apartamentos, las áreas entalladas de administración, de gimnasia o el auditorio se enriquecen espacialmente y permiten relacionarse constantemente con la orientación adecuada proyectándose continuamente sobre la visión dominante del entorno establecida sobre la plataforma. 
Figura 10. Jørn Utzon. Planta de las tipologias de casas patio. Casa para el personal del centro, casa del director, casa de los profesores y del secretario en la Escuela en Højstrup, 1959.

\section{La evolución de la propuesta. Septiembre de 1959}

El proyecto que se desarrolla a partir de la propuesta alternativa, que obtiene el primer premio, se sitúa sobre la variación gradual del terreno que oscila entre la visión dominante del Øresund y la secuencia paisajística que discurre desde la edificación histórica, Højstrupgård, hasta los frondosos bosques y el conjunto de lagos (figura 8). 15

El trazado de los caminos en el bosque, las áreas libres y la ordenación del conjunto se realiza en colaboración del arquitecto paisajista Jørn Palle Schmidt, con quien desarrolla simultáneamente la ordenación de las áreas libres de las casas patio en Fredensborg (1959-1965). La propuesta obtiene de la valoración geográfica, una cuidada relación con el paisaje (figura 9). Se estudian las áreas de aparcamiento que requieren una amplia superficie, la disposición en la ladera de las ocho unidades residenciales, el trazado de los caminos que discurren entre las masas de vegetación, las vias resguardadas en el arbolado configuran esta ordenación de índole paisajística y dotan de carácter al conjunto del centro docente emplazado en la excepcional naturaleza del entorno. ${ }^{16}$

El conjunto de casas patio, que albergan las residencias de los profesores y de los trabajadores del centro, se emplazan en el entorno del centro educativo. La sucesión discontinua de las casas patio compone una secuencia progresiva, gradual y abierta entre las unidades sobre las áreas libres y los ámbitos continuos del bosque. ${ }^{17}$ Los modelos propuestos representan la continua exploración del modelo de casa patio desarrollado por Utzon, ampliando los tipos ensayados en las agrupaciones residenciales Kingo en Helsingør (1956) y se conciben simultáneamente a las unidades propuestas en Fredensborg (1959-1965). ${ }^{18}$
Para Utzon: "la idea consiste en plantear una pequeña casa con algunas habitaciones que además dispone de un patio privado, que nadie puede mirar, y donde se tiene una vista de un área común de la que toda la comunidad participa"(Prip-Buus 2009: 228). ${ }^{19}$

La residencia del director, que se inscribe sobre un rectángulo de $18,5 \times 15,5 \mathrm{~m}$, organiza las tres alas de la edificación, con una crujía de $4,5 \mathrm{~m}$, en torno a un patio (figura 10). En la crujia transversal se produce el acceso a la vivienda que se extiende hacia el patio. La estancia y el ámbito de estudio se conectan espacialmente articulados por el núcleo del hogar y la ala de las habitaciones se abre hacia el patio. Al igual que en las casas Kingo, la variación del plano de la cubierta determina el ámbito de la estancia desarrollado bajo el faldón inclinado de la cubierta o el techo plano proyectado bajo el ala de dormitorios y servicios.

Las cuatro casas patio destinadas a los profesores se plantean como variaciones sobre el modelo de la casa para el director del centro, limitando los accesos de servicios y la relación entre el comedor y la cocina. Las viviendas para el personal del centro albergan un conjunto de seis a ocho apartamentos en cada unidad. Las dos alas longitudinales alojan los apartamentos que se abren hacia el ámbito exterior, mientras las áreas de circulación se desarrollan alrededor del patio y la estancia común, caracterizada por el banco continuo establecido sobre el muro y el hogar situado en la crujía transversal.

La vivienda de menor tamaño, inscrita en un cuadrado de $12,5 \times 12,5 \mathrm{~m}$, desarrolla las características de los modelos anteriores. La posición de la cocina sobre el núcleo de servicios delimita las áreas de circulación de la casa concentrándolas sobre un vestíbulo que se dilata desde el
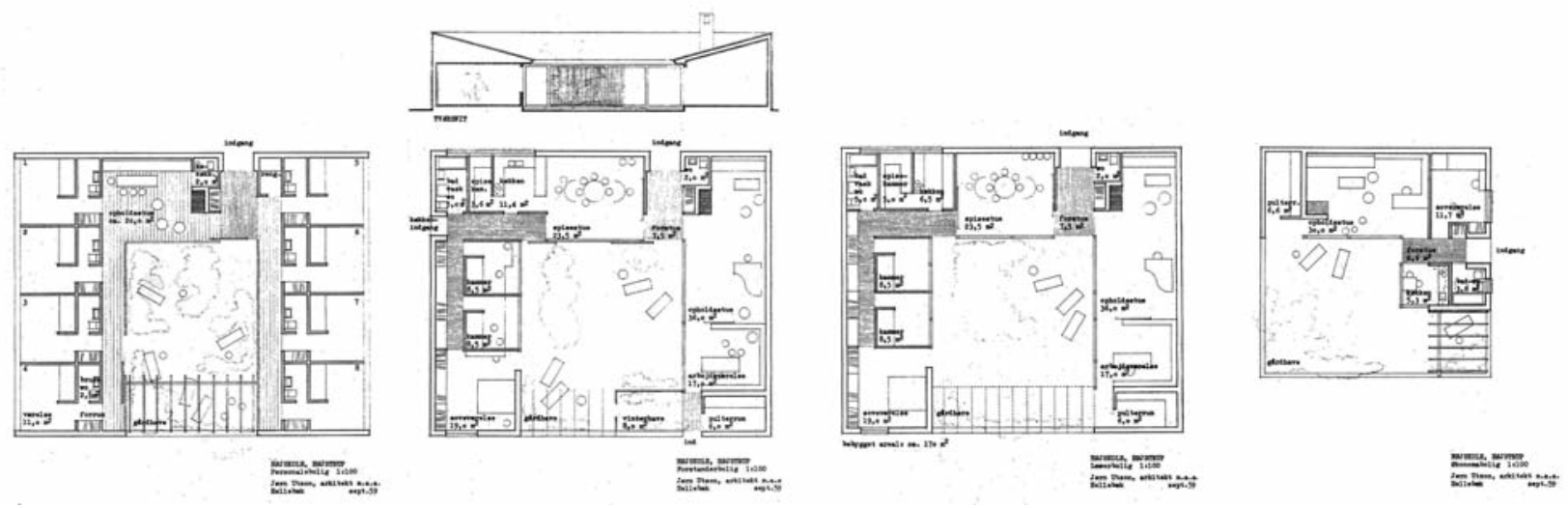


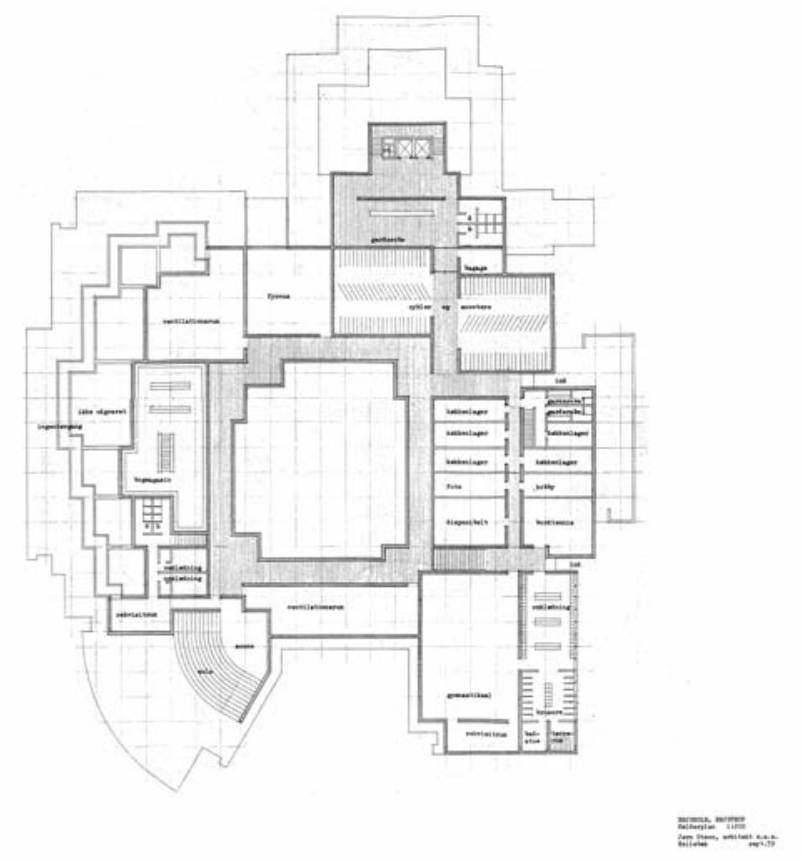

Figura 11. Jørn Utzon. Planta basamental y planta baja de la Escuela en Højstrup, 1959.

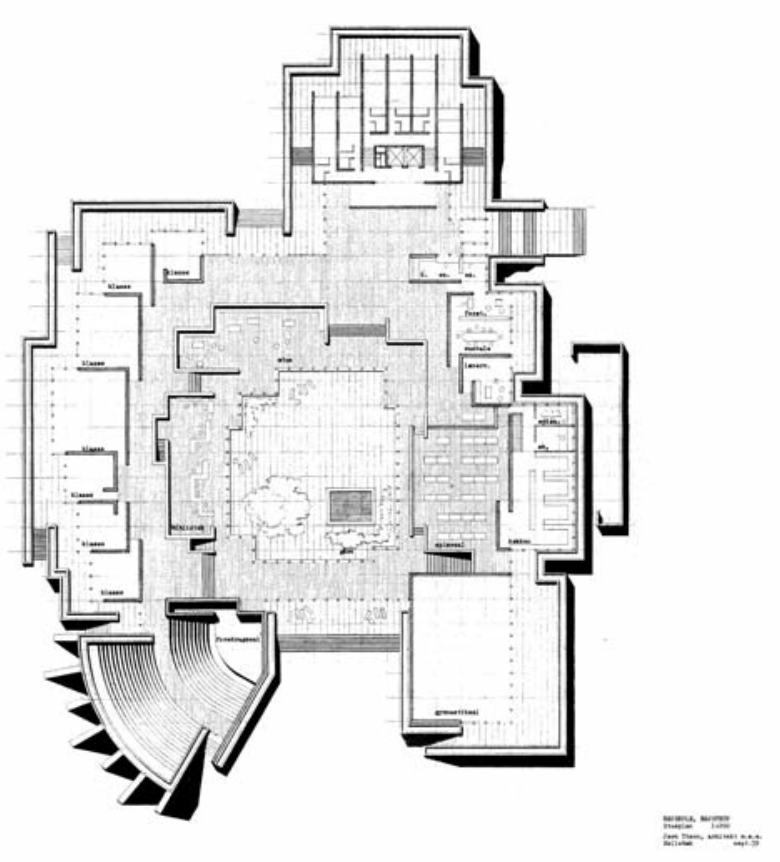

ámbito de ingreso hacia el patio. El vestíbulo se extiende frontalmente hacia el patio y tangencialmente hacia la estancia caracterizada por el vínculo establecido entre el hogar y el banco situado en el muro de abrigo enfatizando la relación térmica y contemplativa entre la lumbre del hogar y el medio exterior. Del mismo modo que realiza en la casa del arquitecto (1952) y en la casa Andersen (1953), "en una casa europea uno quiere sentarse junto a la pared," escribe Jørn Utzon (Utzon 1962: 114-117).

El acceso tangencial al centro docente se produce desde el flanco oriental. El trazado del camino y la pendiente del terreno natural producen una tenue inflexión en la posición del centro que oscila entre el desnivel del entorno y la suave curvatura del camino de acceso. El desnivel del terreno requiere proyectar el terreno para el asentamiento, sobreelevándolo con una plataforma que sigue las cualidades especificas del terreno evocando las plataformas mayas. Para Utzon: "todas las plataformas mexicanas fueron ubicadas y construidas con una gran sensibilidad en su apreciación del entorno natural" (Utzon 1962: 114-117).

La escuela se desarrolla sobre una plataforma que contiene, a modo de basamento, el programa complementario del centro y alude a la plataforma de Aalto en el Ayuntamiento de Säynatsalö (1949-1952). Destinado a los espacios servidores, el aparcamiento de bicicletas, los almacenes, los vestuarios y las dependencias auxiliares proporcionan apoyo a las actividades que se desarrollan sobre la plataforma. El basamento destinado a establecer un suelo artificial cuya organización interior gravita en torno a un patio reproduce en su interior la berma de tierras, el patio, que envuelve el programa de servicios del basamento. ${ }^{20}$

Compuesto sobre un módulo de 3 × $3 \mathrm{~m}$, el programa de la escuela se desarrolla sobre la plataforma en torno a un patio que acentúa la relación con el medio continuo y contrasta con el volumen compacto de la torre que se yergue en el extremo del conjunto.

El acceso se produce tangencialmente entre el cuerpo de la torre y el recinto de la escuela. Se ingresa a través de un amplia escalera que desborda los limites de los muros y conduce al nivel superior del podio donde se desarrolla el programa docente y se erige el volumen de la torre de apartamentos para los estudiantes. En el perímetro quebrado de la plataforma del centro se sitúan los distintos accesos en las inflexiones de los muros y el interior del recinto de la escuela se desarrolla en una comunicación fluida y gradual, a través de las distintas áreas y de los distintos niveles.

El conjunto de las siete aulas se sitúan en el extremo de la plataforma donde el auditorio que corona el flanco occidental del conjunto se extiende sobre el medio fisico. El programa complementario, la biblioteca y las estancias colectivas se disponen, a medio nivel, sobre el patio. Mientras el gimnasio que determina el flanco oriental, se extiende sobre los ámbitos colectivos del comedor, el área administrativa y se des- 


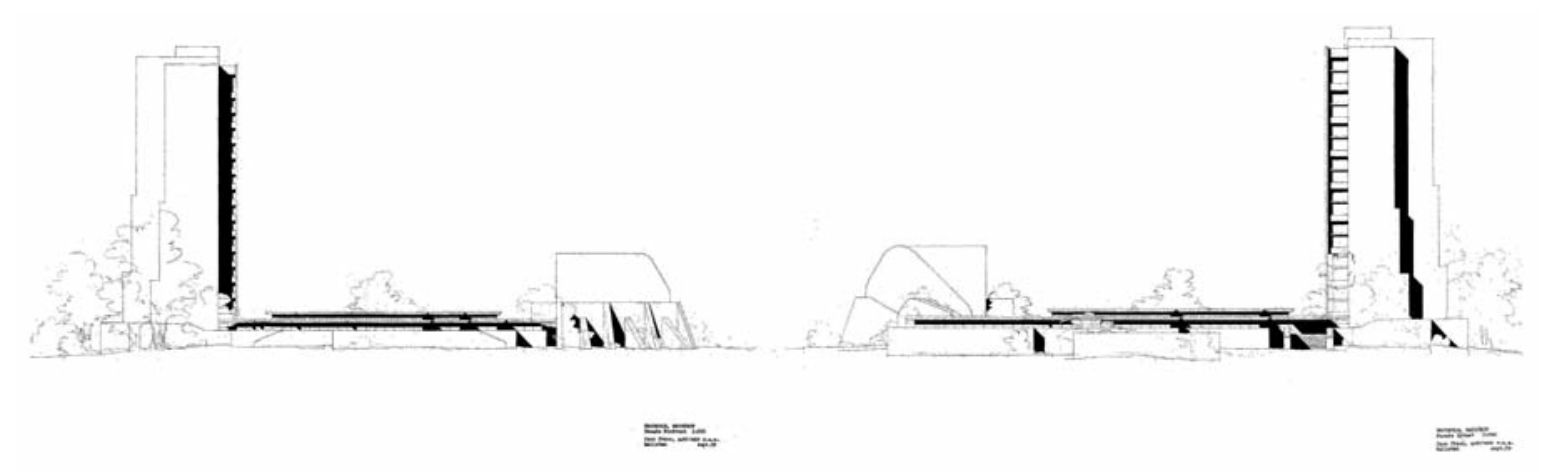

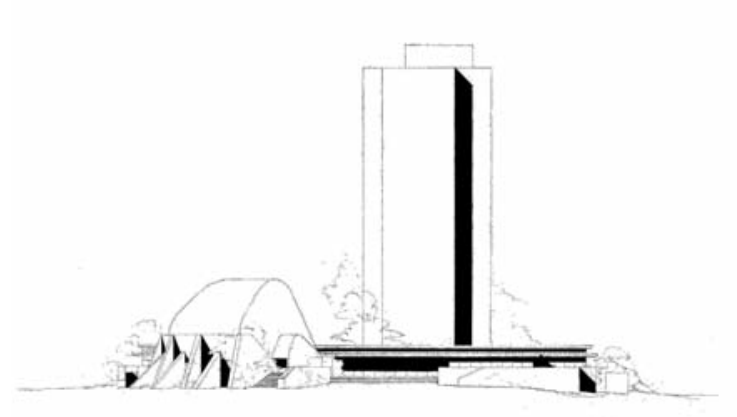

푼다-

Figura 12. Jørn Utzon. Alzados de la Escuela en Højstrup, 1959.

Figura 13. Jørn Utzon. Planta alternativa del tipo de los apartamentos de la torre de la Escuela en Højstrup, 1959.
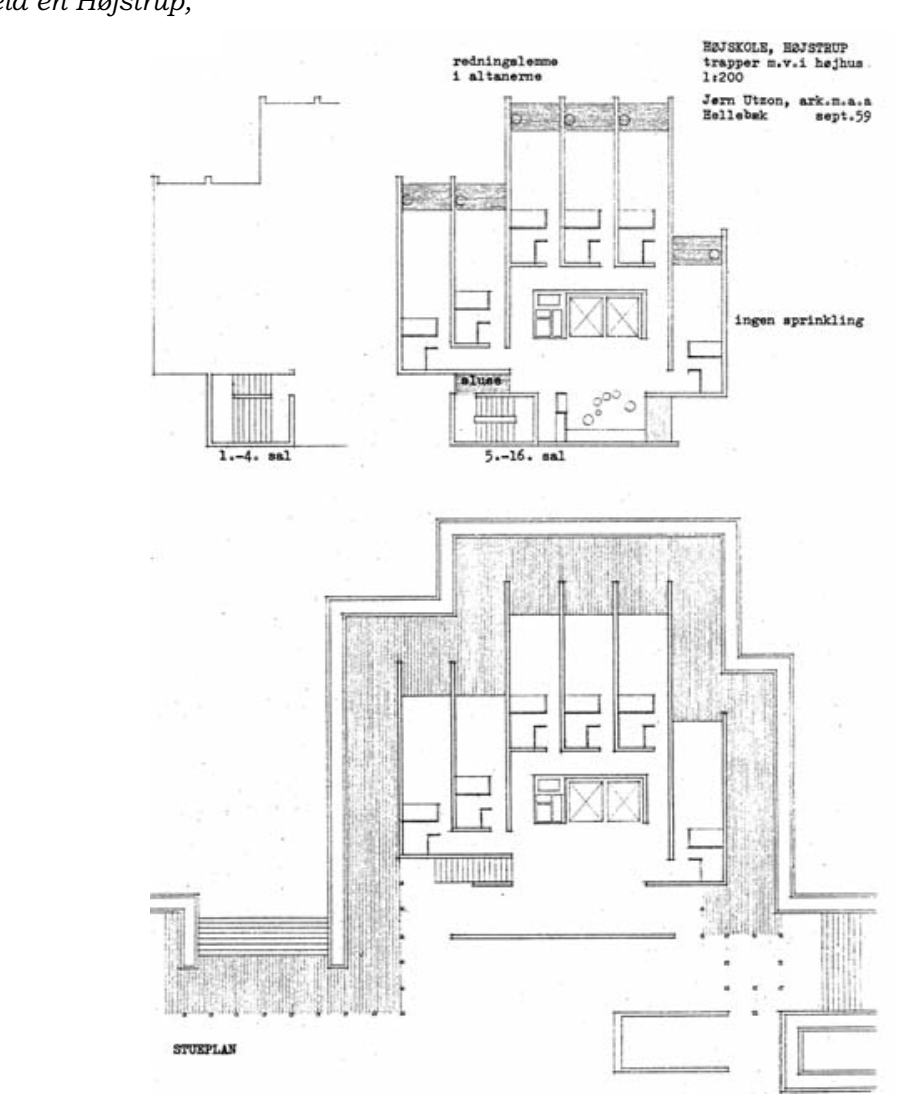

arrollan alrededor de un patio-jardin abierto que se proyecta a través de una galería inmaterial sobre la naturaleza del medio continuo.

En el interior se vinculan las unidades docentes con las estancias interiores por medio de desniveles: el superior caracterizado por la sucesión continua de aulas o unidades administrativas, establecidas sobre el módulo compositivo, que distribuyen en torno al ámbito de circulación, el acceso tangencial a las distintas aulas o salas; el inferior determinado por el patio deprimido en el que se subraya un estanque donde convergen las actividades de la biblioteca y la estancia. ${ }^{21}$ De este modo, la plataforma que delimita el recinto de la escuela, se amplía hacia el ámbito interior, cuyas actividades contemplativas y recreativas se prolongan sobre el patio.

La estructura superpuesta del plano de la cubierta introduce la iluminación en las áreas interiores y subraya la levedad de las cubiertas sobre el valor delimitador de los muros del recinto de la escuela (figura 12). Enfatizando la composición por partes, el cuerpo del auditorio y el programa del gimnasio delimitan los extremos del recinto de la escuela, mientras la torre se erige en el vértice de la propuesta orientándose hacia el Øresund.

El cuerpo singular del auditorio, cuya sección triangular se genera en el desarrollo de la directriz planimétrica del anfiteatro, emerge de la plataforma masiva cuya forma radiante concilia las ingrávidas cáscaras con la plasticidad de los contrafuertes que tiene en el pretil continuo del muro que delimita la plataforma la alteración del orden regular de la plataforma y el ámbito continuo de vegetación. Del mismo modo que en la Ópera de Sídney, la distorsión 


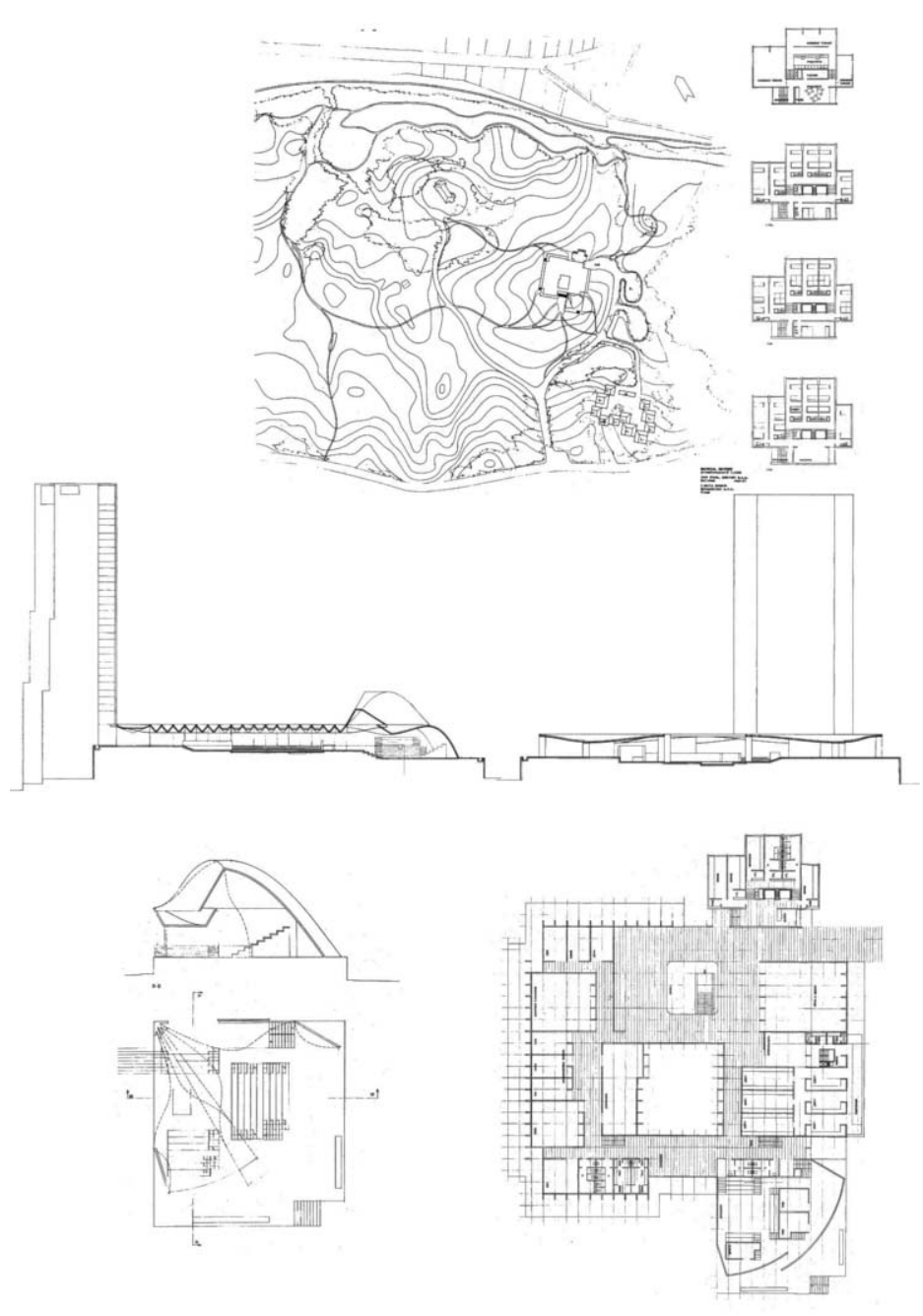

Figura 14. Jørn Utzon. Emplazamiento, secciones y detalle de las plantas de la Escuela en Højstrup, 1961. del orden regular se produce al girar los cuerpos de los auditorios que convergen sobre el ámbito de la plataforma. En la escuela, la desviación del auditorio de la trama compositiva del conjunto acentúa la fuerza del auditorio como foco visual que emerge sobre el suelo de la plataforma masiva.

El volumen del gimnasio se entalla en la plataforma y el suelo de la pista polideportiva se sitúa en el nivel inferior. A través del cerramiento situado en el nivel superior, introduce la luz en el interior, en un mecanismo ensayado en el concurso para la ampliación del estadio de Aarhus (1947).

En el vértice del recinto de la escuela se yergue el cuerpo de la torre, de 16 plantas, compuesto por la agregación de apartamentos que con una crujía de $3 \mathrm{~m}$ se extienden sobre la trama compositiva del conjunto. Las unidades se agrupan en torno al núcleo vertical de comunicación cuya escalera desplaza media altura los apartamentos de los extremos. En la solución alternativa incorpora un ámbito comunitario, segrega la escalera y sitúa todos los apartamentos en el mismo nivel (figura 13). Mientras los apartamentos se orientan hacia el Øresund a través de la variación gradual establecida en la terraza y en el perfil quebrado de la torre que ensaya en las torres de viviendas de Elineberg en Helsingborg (1954).

\section{La porte-cochère: la experiencia de Sidney. Septiembre de 1961}

La plataforma se vincula con la red de caminos para recoger, mediante las escaleras y los ámbitos receptivos de ingreso establecidos en el basamento, los accesos a la escuela. En la ordenación del conjunto de las residencias para profesores y per-
Figura 15. Jørn Utzon. Planta baja y planta cubiertas de la Escuela en Højstrup, 1961.

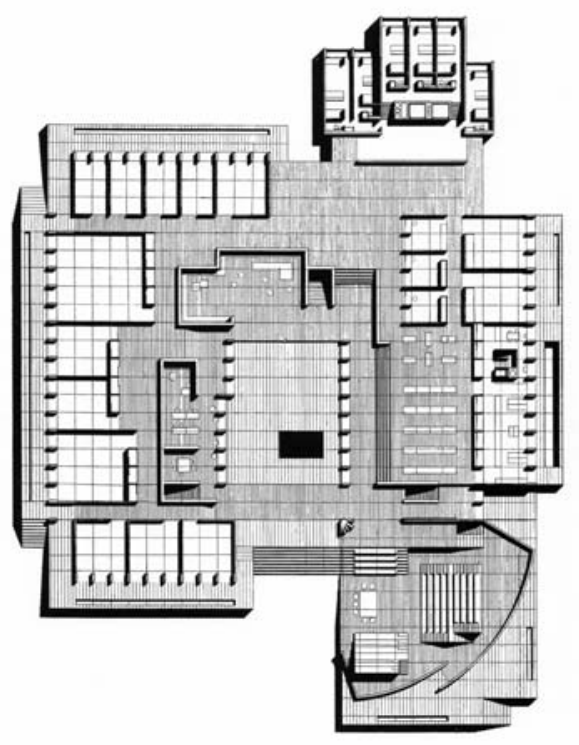


Figura 16. Jørn Utzon. Alzados de la Escuela en Højstrup, 1961. sonal, Utzon retoma las experiencias de las unidades de agregación de la casas patio en Helsingør (1956), Bjuv (1956) o Lund (1956-1957) (figura 14). En la torre de apartamentos recurre a la experiencia del proyecto de viviendas en Elineberg en Helsingborg (1954) y en el centro docente compendia las soluciones precedentes con el desarrollo estructural planteado en la construcción de la Ópera de Sídney (19561973). ${ }^{22}$

La primera fase de la Ópera de Sídney dedicada a la construcción de la plataforma se convierte en la referencia estructural de la escuela en Højstrup (Weston 2002: 222). El mecanismo de acceso producido a través de la porte-cochère y las losas plegadas que alcanzan una luz de 50 $\mathrm{m}$ determinarán la estructura de la cubierta de la escuela (Asgaard Andersen 2014: 132). La propuesta se realiza en septiembre de 1961, simultáneamente a la elaboración de los esquemas estructurales de la cubierta de la Ópera de Sídney y antes de encontrar, en octubre de 1961, la solución definitiva para las bóvedas de la cubierta con el modelo esférico.

La escalera que asciende tangencialmente entre el cuerpo de la torre y el recinto de la escuela se convierte en una porte-cochère que accede a través del basamento de la plataforma al anillo de las instalaciones y los servicios planteados en torno a la berma del patio. ${ }^{23}$ En el interior, la escalera que asciende tangencialmente desde el basamento al nivel de la plataforma y se abre al patio principal (figura 15).

La propuesta establecida sobre un módulo de $2 \times 2 \mathrm{~m}$, presenta variaciones en cuanto al programa del centro (Faber 1968: 123). Se contempla la disposición de más aulas que complementan el programa educativo del centro y se prescinde del ámbito deportivo del gimnasio. De este modo, los extremos del recinto quedan determinados por la torre situada como vértice del conjunto y el volumen del auditorio que ocupa la posición del gimnasio del modelo precedente. Mientras el ámbito de las aulas se extiende sobre el flanco occidental del conjunto, las aulas de seminarios y las unidades de pequeños grupos se orientan al norte y al sur respectivamente. En cambio, las cuatro aulas mayores se abren a la orientación a poniente.

El área administrativa, el comedor o las estancias colectivas y la biblioteca situados en el nivel inferior del recinto mantienen la posición en el conjunto regularizando su configuración. La cubierta del recinto de la escuela se establece sobre la referencia de la porte-cochère desarrollada en Sídney. Las losas plegadas quedan determinadas por la transición gradual de la sección, en relación a la variación de los momentos que oscilan entre los negativos
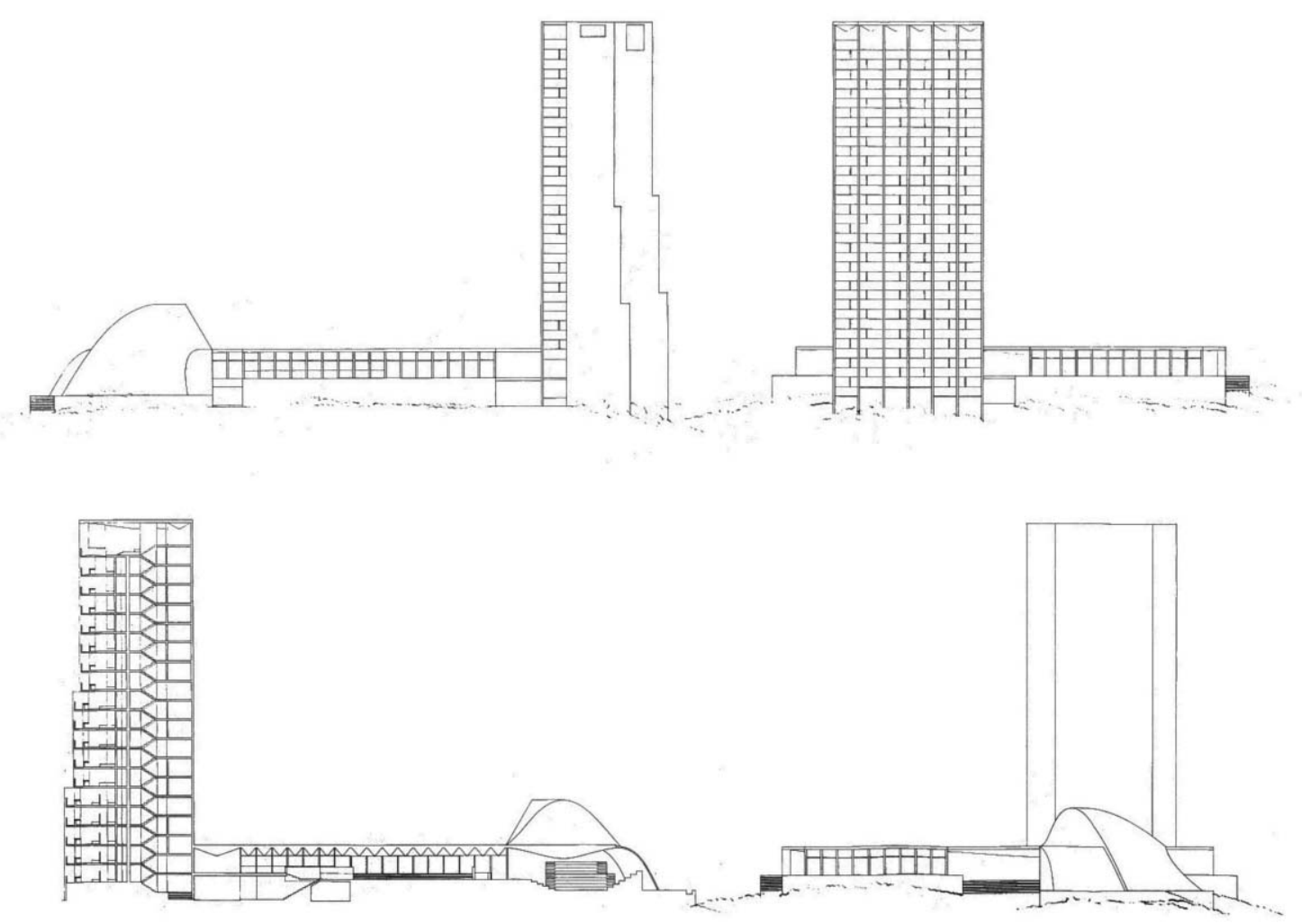
Figura 17. Jørn Utzon. Planta tipo de los apartamentos de la torre de la Escuela en Højstrup, 1962. en los extremos y los positivos en el centro del vano. De este modo, las losas plegadas que indican la distribución de fuerzas se apoyan sobre los esbeltos pilares de $100 \mathrm{x}$ $20 \mathrm{~cm}$ y salvan una luz que varía desde los $6 \mathrm{~m}$ del ámbito de las aulas hasta los $28 \mathrm{~m}$ del vestíbulo principal.

La estructura del recinto de la escuela contrasta con la vibración de las cáscaras geométricas que alojan el área del auditorio cuyo modelado escultórico emerge sobre el ámbito de la plataforma. Como contrapunto, el cuerpo opaco de la torre, compuesto por la agregación de apartamentos de $3 \mathrm{~m}$ de crujia, se contrapone a la levedad de las losas plegadas y las cáscaras del auditorio (figura 16).

Simultáneamente al desarrollo de esta versión del proyecto Utzon escribió en la revista Arkitekten una crítica al proyecto ganador del concurso para la Universidad de Estocolmo de Henning Larsen caracterizada por una plataforma masiva sobre la que destacan las cubiertas de los auditorios compendiando muchos de los rasgos significativos de los proyectos de Utzon. Ilustraba su breve artículo con el proyecto de la Escuela en Højstrup y el proyecto para la Exposición Internacional en de Copenhague reclamando "paz para trabajar y seguir desarrollando mis proyectos de plataformas que se han desarrollado a través de un trabajo duro y arduo, así como de mis experiencias en viajes a lugares como México, India y China" (Utzon 1961: 290) a lo que Henning Larsen replicaba con la constante recurrencia a la plataforma en la tradición moderna en las obras de Wright, Le Corbusier, Niemeyer o Aalto (Larsen 1961: 291).

\section{Desenlace y polémica. Marzo de 1962}

En la siguiente evolución del proyecto las variaciones se concentran en la sistematización de la torre de apartamentos y en recuperar la configuración inicial del acceso al centro a través de una amplia escalera que conduce al nivel superior de la plataforma, descartando el mecanismo de acceso a través de la porte-cochère que generaba un ámbito receptivo de ingreso en el interior del basamento.

El volumen de la torre se contrae y adopta una disposición más longitudinal y se sitúa tangencialmente sobre la plataforma de la escuela. El apartamento que ocupaba la crujía sur se desplaza sobre el frente de la torre. De este modo el volumen presenta una organización más compacta con el frente de los apartamentos orientados al Øresund mientras, las estancias colectivas ocupan el frente posterior de la torre y se desarrollan en doble altura enfatizando el valor social otorgado a las estancias públicas. Del mismo modo, el excepcional ámbito colectivo que coronaba el cuerpo de la torre se abandona.

Las 16 plantas que alojan los apartamentos de los estudiantes residentes se contraen en el perfil quebrado y sucesivo de la torre en altura donde los apartamentos
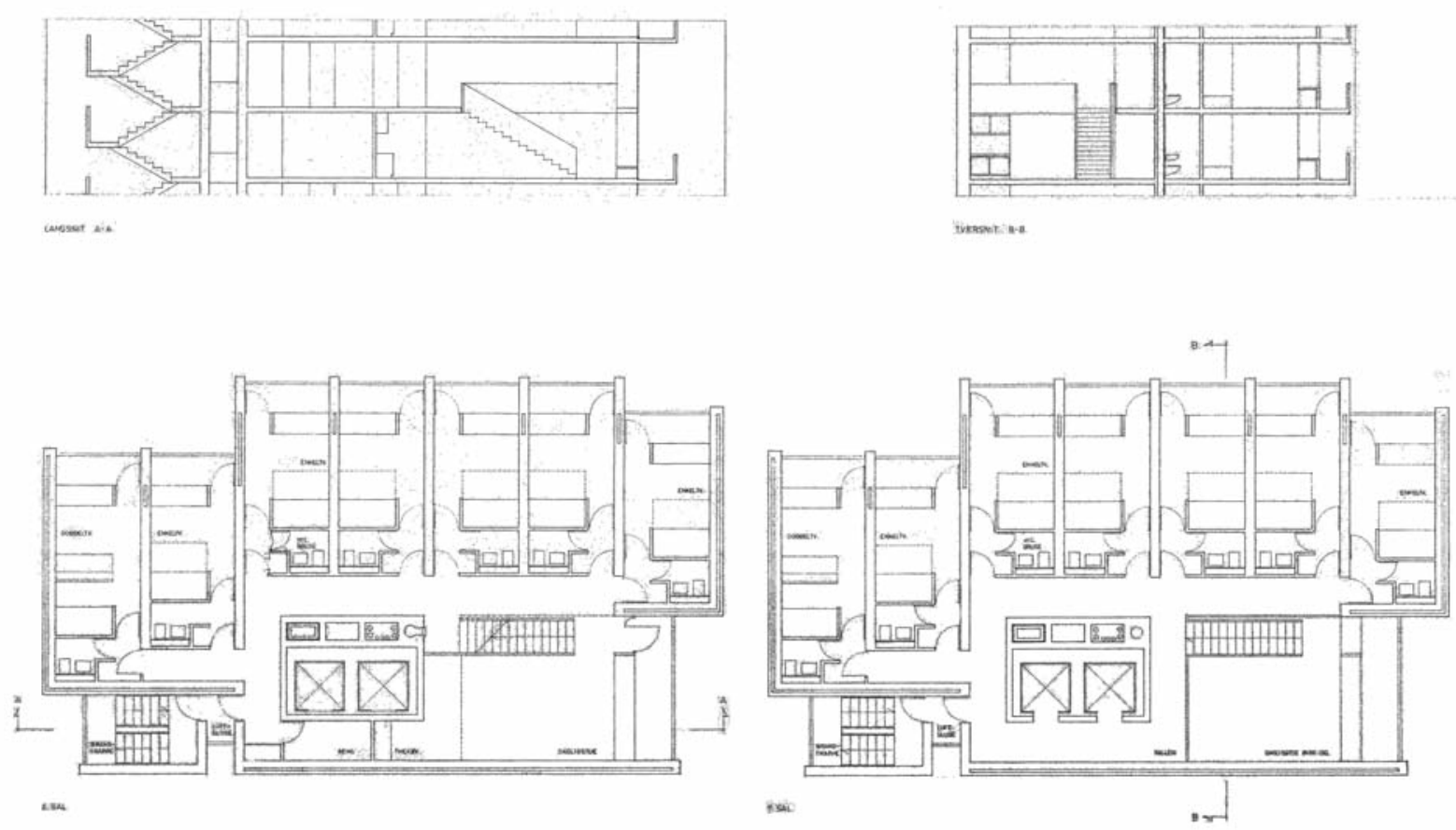
dobles ocupan los niveles inferiores y los individuales, los superiores. El cuerpo de la torre se erige sobre los ejes estructurales del recinto educativo que en forma de pantallas de hormigón continuo, a través de encofrados deslizantes, recuperan la tecnología con la que estaba previsto edificar las viviendas de Elineberg (19541966).

La esbeltez de la torre que emerge sobre los frondosos bosques en la franja del litoral de la costa que se extiende sobre el Øresund suscita un intenso debate. ${ }^{24} \mathrm{El}$ incremento de la controversia y la acentuación de la polémica con la exposición del proyecto suscita la suspensión del controvertido proyecto y el alejamiento de Utzon que se desplaza en diciembre de 1962 a Sídney para seguir el desarrollo de la construcción de la segunda fase de la Ópera de Sídney. ${ }^{25}$

La propuesta entonces se encarga al equipo de Jarl Heger y Ebbe y Karen Clemmensen que habian obtenido el segundo premio en el concurso. El proyecto del concurso caracterizado por un extenso bloque lineal se transforma en un conjunto de pabellones determinados por la secuencia rítmica de los volúmenes acentuados por la levedad de los faldones de la cubierta y el carácter paisajístico de la composición (Birger 1994: 58-63).

\section{Conclusión}

En una entrevista en 2008, Jørn Utzon retoma el análisis de los proyectos planteados en Højstrup: "realicé dos propuestas para la Escuela de la Unión de trabajadores daneses en Højstrup aquí en Helsingør; Una propuesta era un edificio alto, una especie de rascacielos que a ninguno de los interesados le gustaba porque sólo era posible que cinco o seis estudiantes a lo sumo salieran de sus habitaciones $u$ otras dependencias y se encontraran en el pasi1lo"26 (Prip-Buus 2009: 227). Así, Utzon se inclina por la propuesta que obtuvo el tercer premio y que desarrollaba todo el programa en un recinto emplazado sobre una plataforma que adopta una importante función como lugar de encuentro, complementando la componente de relación social del centro educativo y convirtiéndose así en un lugar de estancia colectiva que constituye uno de los valores de la ciudad. Así, Kenneth Frampton interpreta la escuela de Højstrup como una "ciudad en miniatura" (Frampton 1999: 257). Para Rafael Moneo, el plano horizontal, la plataforma que construye Utzon "establece la distancia necesaria con el medio y construye un espacio público" (Moneo 1995: 19).
En el artículo titulado "La importancia de los arquitectos" (Utzon 1984), Utzon describe la lenta y paciente búsqueda del proyecto arquitectónico que se ilustra en el proceso de proyecto de la Escuela en Højstrup: "el trabajo creativo del arquitecto es de una naturaleza tan complicada que para obtener resultados satisfactorios son necesarios un enorme número de dibujos y maquetas. La mayor parte de este trabajo puede parecer inútil. En el proceso de depuración y entrelazado de las distintas partes y funciones de un edificio se suele trabajar con tantas alternativas a fin de encontrar la idónea- que hasta el noventa por ciento del trabajo puede ser desechado. En vez de quejarse de este derroche, hay que compararlo con la derrochadora abundancia de la naturaleza. Le Corbusier lo expresó en estos consoladores términos: el trabajo del arquitecto nunca se pierde; el trabajo realizado en cada obra contiene algo útil para la siguiente" (Utzon 1995: 12).

Para Utzon, toda obra maestra es el resultado de un intenso proceso de trabajo donde confluye la audacia estructural, la sintesis formal y la excelencia funcional y paisajistica. Discípulo de los grandes maestros escandinavos Asplund y Aalto y admirador de Wright ó Mies, los proyectos de Utzon, no permanecieron ajenos a la evolución de la arquitectura moderna, pero surgieron invariablemente a partir de una rigurosa reelaboración personal. Para Utzon, el arquitecto "debe experimentar, practicar como hace el músico con sus escalas, practicar con masas, con ritmos creados por la agrupación de masas, combinaciones de colores, luz y sombra, etc. Debe percibirlos intensamente y desarrollar y poner en práctica sus cualidades" (Utzon 1995: 15). El análisis del proyecto para la Escuela de Højstrup permite aproximarnos tanto al intenso proceso de exploración arquitectónica como a los innumerables hallazgos constructivos $\mathrm{y}$ formales de su talento formal y su legado innovador, en una arquitectura lírica y singular que reivindica la lógica estructural, la precisión geométrica y la integración en el paisaje.

\section{Notas}

1 "What I probably learned most from him, and also from Arne Korsmo, is the poetry that lies in adding a thing to a place in a way so that it fits into that place." Traducción del autor.

2 Los resultados de la convocatoria se publican en la revista Arkitekten. "Konkurrencen om en højskole ved Helsingør", Arkitekten 6 (1959): 101-113. El jurado compuesto por Tobias Faber, Viggo Sten Møller y Jørgen Stærmose otorga el primer y el segundo premio a los pro- 
yectos presentados por Utzon, el segundo premio se concede a la propuesta de Jarl Heger, Ebbe y Karen Clemmensen. El extenso bloque lineal, de $180 \mathrm{~m}$ de largo, de los Clemmensen y Heger presenta un frente ciego al Øresund, mientras en la cubierta, sobre las tres plantas del conjunto, se dispone un amplio mirador que discurre sobre los apartamentos de los estudiantes y que ofrece unas amplias vistas sobre el Øresund y la ciudad de Helsingør. Cuando Utzon abandona el proyecto para dedicarse completamente a la Ópera de Sídney, los Clemmensen construyen una propuesta alternativa basada en distintos pabellones agrupados en torno a un conjunto de patios.

3 Información proporcionada por Nils-Erik Nielsen de la LO-Skolen Helsingør y publicada en: Birger Mikkelsen, Fra vision til virkelighed. Historien om LO-Skolens tilblivelse (Helsingør, 1994).

4 Programa de la convocatoria del concurso: Program foroffentlig projekt-konkurrence om skisteforlag til en Højskole ved Helsingor, junio de 1958. El programa de la escuela destinado a establecer una escuela de invierno para alumnos de 18 a 25 años, unos cursos de verano de 1 a 3 semanas, así como organizar conferencias, seminarios y reuniones, se organiza sobre un conjunto de siete aulas, una aula de $90 \mathrm{~m}^{2}$, otra de $75 \mathrm{~m}^{2}$ y cinco unidades de $35 \mathrm{~m}^{2}$, que tienen en la sala de conferencias o auditorio, de 170 plazas, el foco principal de la escuela. Asimismo, el centro debe disponer de una amplia biblioteca, un gimnasio polivalente destinado a 60 alumnos y además ofrecer alojamiento a través de 100 apartamentos para los estudiantes residentes. El conjunto se completa con un área administrativa y los locales de almacén y servicios.

5 "I studied hundreds of pictures, photographs and maps of the site" Traducción del autor. Dane's controversial Design wins Opera House contest. Phone talk to winner", en The Sydney Morning Herald, 30 de enero de 1957.

6 Situado junto al terreno de la Escuela de Højstrup, y en el transcurso de la redacción del proyecto realizará un anteproyecto de un conjunto de viviendas Birkehøj (1960) que ilustra el interés de Utzon por este emplazamiento.

7 Las dos primeras firmadas por Alvar Aalto y la tercera por Aino Aalto.

8 Al igual que en la propuesta del concurso de la Ópera de Sídney (1956), el podio queda delimitado por una jardinera que actúa como limite de la plataforma.

9 De este modo, se evita también la sombra de la torre sobre el centro docente de la primera opción. Sin embargo, la valoración de la sombra en la primera propuesta parece soslayarse en su representación sobre el emplazamiento, donde se presenta una sombra arrojada matinal.

10 La plataforma que establece el programa del centro se delimita por un muro perimetral que contiene, en el pretil del muro, un ámbito continuo de vegetación.

11 "The platform stands in a slightly undulating landscape and emphasizes, by its squareness and straightness, the soft movements of the landscape". Traducción del autor.

12 El proyecto, organiza las viviendas en bloques aterrazados en torno a un recinto caracterizado por el desnivel que alude a la disposición en abanico de las viviendas de Kauttua de Aalto (1937-1940) y que finalmente será construido por Halldor Gunnlogssøn en 1970. (Frampton 1999: 254)

13 "Great care has been taken to follow the landscape and to utilize its values". Traducción del autor.

14 "They stand forth as self-evident and enduring part of the place". Traduccion del autor.

15 Información facilitada por Anette Eklund Hansen y el ABA, Arbejderbevægelsens Bibliotek og Arkiv, Copenhague.

16 Los caminos trazados sobre el entorno se dividen en los privados, destinados a los estudiantes del centro que se extienden sobre el paraje continuo del terreno fluctuante y los caminos públicos que discurren sobre el paraje del centro delimitados por zanjas continuas que determinan el ámbito privado del terreno.

17 La secuencia transita desde la residencia del director (f) situada en el inicio de la vía a las cuatro casas patio para los profesores (l) que se desplazan sobre el desnivel y concluye con la casa para el secretario económico (ø) y las viviendas para el personal del centro $(\mathrm{p})$.

18 Mientras el desarrollo de las unidades de Fredensborg se realiza en diciembre de 1959 el conjunto de la escuela de Højstrup está fechado el septiembre de 1959.

19 "The whole idea consists of having a small house with some rooms, and then you have your own private courtyard just outside, which no one can look into, and where you have a view of a common area that everyone can have a share of". Traducción del autor.

20 Un muro aislado se separa del conjunto de la plataforma y ampara el ámbito de servicios del basamento asi como los accesos de servicios que se producen en el pliegue de los muros de la plataforma. Mientras, el pretil del muro que contiene un ámbito continuo de vegetación subraya los límites del recinto de la escuela.

21 De este modo el interior de la escuela fluye en continuidad sobre las distintas áreas, el desnivel delimita los distintos ámbitos sin encerrarlos. Los 70 centimetros que separan los distintos niveles del interior se convierten en un ejercicio de estudio donde se desarrollan distintas alternativas a escala 1:20. Las áreas de circulación que caracterizan el nivel superior del centro, determinado por el plano del techo continuo y plano a $2,26 \mathrm{~m}$, fluyen visualmente sobre los ámbitos inferiores destinados a la biblioteca o la estancia colectiva. El muro que articula las distintas áreas, de 40 $\mathrm{cm}$ de grosor, transita desde la estantería continua de la biblioteca al pretil del muro que contiene un ámbito continuo de vegetación, donde se entabla una conversación, se produce un encuentro o se apoya un banco.

22 La sucesión de viviendas para profesores y personal del centro adopta una configuración continua que abarca un ámbito común de acceso, en la que cada unidad se establece en el desnivel del terreno sobre la variación gradual del entorno.

23 El acceso se produce en el mismo ámbito que en la propuesta anterior. La plataforma se vincula con la red de caminos para recoger, mediante las escaleras y los ámbitos receptivos de ingreso establecidos en el basamento, los accesos a la escuela.

24 El proyecto de la Escuela en Herning de Viggo Møller Jensen y Tyge Arnfred (1962) adopta una configuración formal muy similar al proyecto de Utzon en Højstrup combinando la esbelta torre de habitaciones con la articulación de recintos y pabellones que contienen el programa educativo del centro. (Faber 1968: 124-125)

25 Utzon retomará el proyecto de la torre de apartamentos en la residencia social Alderdomshjem, emplazada en el centro de Helsingør, (1962-1966), donde el carácter escultórico del perfil quebrado de la torre de ocho plantas se alza sobre la línea de cornisa de la ciudad y acoge en la planta superior una estancia mirador. La construcción de la residencia asistencia en Helsingør la realizará Birger Schmidt.

26 "I made two proposals for a folk high school 
for the Confederation of Danish Trade Unions here in Elsinore; one was a tall building, a sort of skyscraper that none of the people concerned liked because it was only possible for five or six at the most to come from their offices or other rooms and meet in the corridor." Traducción del autor.

\section{Bibliografia}

AsgaARD Andersen, Michael. 2014. Jørn Utzon. Drawings and Buildings. New York: Princeton Architectural Press.

FABER, ToBIAs. 1968. Neue dänische Architektur. Stuttgart: Verlag Gerd Hatje Stuttgart

FRAMPTON, Kenneth.1999. Estudios sobre la cultura tectónica. poéticas de la construcción en la arquitectura de los siglos XIX y XX. Madrid: Ediciones Akal.

Fromonot, Françoise. 2003. Un moderno inclasificable. Jørn Utzon, premio Pritzker 2003, Arquitectura Viva, 89-90:123-125.

Giedion, Sigfried. 1965. Jørn Utzon and the third generation. Zodiac, 14: 36-47.

Konkurrencen om en højskole ved Helsingør. Arkitekten, 6: 101-113.

LARSEN, Henning. Svar fra Henning Larsen. Arkitekten: 291.

Mikkelsen, Birger. 1994. Fra vision til virkelighed. Historien om LO-Skolens tilblivelse. Helsingør.

MARTIEnssen, Rex D. La idea del espacio en la arquitectura griega. Buenos Aires: Nueva Visión, 1957.

Moneo, Rafael. 1995. Sobre la arquitectura de Jørn Utzon: apuntes cordiales. En: Jørn Utzon. A Coruña: Ministerio de Obras Públicas, Transportes y Medio Ambiente y Fundación Barrié de la Maza.

NorberG-Schulz, Christian. 1996. Nightlands. Cambridge: MIT Press.

Prip-Buus, Mogens. 2009. Utzon. Additive Architecture, Hellerup: Edition Bløndal.

Utzon, Jørn. 1959. Birkehöj. Zodiac, 5: 90.

UTZON, Jørn. 1961. Om Stockholm universitet. Arkitekten: 290

Utzon, Jørn. 1962. LO Højskolen. Zodiac, 10: 140.

UtZon, Jørn. 1962. Platforms and Plateaus: Ideas of a Danish Architect. Zodiac, 10: 114-117.

Utzon, Jørn. 1984. The importance of architects. En Architecture in an age of skepticism, Denys Lasdun. Londres: Heinemann.

Utzon, Jørn. 1986. Om Arne Korsmo. En: NorbergSchulz, Christian. Arne Korsmo. Oslo: Universitetsforlaget.

Utzon, Jørn. 1995. Jørn Utzon. A Coruña: Ministerio de Obras Públicas, Transportes y Medio Ambiente y Fundación Barrié de la Maza.

Weston, Richard. 2002. Utzon. Inspiration. Vision. Architecture. Hellerup: Edition Bløndal.

Weston, Richard, Pardey, John. 2002. Platform: explorations of an architectural idea. Arq Achitectural Research Quarterly, vol. 6 n. 2: 145-157.
Fecha final recepción artículos: 24/04/2016

Fecha aceptación:

19/06/2016

Articulo sometido a revisión por dos revisores independientes por el método doble ciego. 